\section{MS14-P3 Characterization of ceramics from Inner Mongolia using complementary diffraction techniques} Ralph Gilles ${ }^{\mathrm{a}}$, Ioannis M. Siouris ${ }^{b}$, Dirk Visserc, W. Kockelmann $^{\text {d }}$, S. Katsavounis ${ }^{\mathrm{b}}$, M. Hoelzel ${ }^{\mathrm{a}}$, Jens M. Walter ${ }^{\mathrm{e}}$, M. Brunelli ${ }^{\text {a }}$ Technische Universität München, ForschungsNeutronenquelle Heinz Maier-Leibnitz (FRM II), Germany,

${ }^{b}$ Democritus University of Thrace, Dept. of Production and Management Eng., Greece, ${ }^{c}$ Reactor Institute Delft, Department RRR-FAME, TU-Delft, Netherlands, ${ }^{d}$ STFC Rutherford Appleton Laboratory, Chilton,United Kingdom, ${ }^{e}$ Geowissenschaftliches Zentrum der Universität Göttingen (GZG), Germany, ${ }^{f}$ European Synchrotron Radiation Facility, BP 220, France

E-mail: Ralph.Gilles@frm2.tum.de

In the present study ceramic sherds typical for the Inner Mongolia area have been analysed using both neutron (ND) and X-ray diffraction (XRD), including synchrotron radiation (SR-XRD) as complementary probes in extracting information on the mineral composition as well as on the firing conditions during the production of the sherds [1]. The data evaluation was performed with the standard diffraction analysis package GSAS and the new developed program AmPhOrAe. The results show that all ceramics present similar mineralogical characteristics. The dominating phase is mullite $(\sim 60 \%)$, whereas the variable mixtures of $\mathrm{SiO}_{2}$ phases (quartz/ cristobalite) are of $\sim 35 \%$ and to a lesser extend feldspar phases. In addition thin sections of the sherds were prepared for microscopic to investigate the grain fabrics and their influence on the various ceramic sherds.

The study describes the phase analysis on four sherd pieces. With the new program AmPhOrAe, which is specialized on archaeological studies including amorphous contributions, it was possible to enlarge the information on additional phases and amorphous contribution in the sherds from better background studies in comparison to the program GSAS. The results clearly prove the coexistence of high and low cristobalite at room temperature. Measurements of one sherd with thin coating structure yield further phases (such as anorthite) which are most probably hidden in the diffraction patterns of the bulk phases. Refiring experiments on one of the sherds allow estimating the firing temperatures of the ceramics within the region of $1150^{\circ} \mathrm{C}$ and $1250^{\circ} \mathrm{C}$.

[1] Gilles, R., Siouris, I.M., Visser D., Kockelmann W., Katsavounis S., Hoelzel M., Walter J., Brunelli M., Journal of the European Ceramic Society (2012), in preparation.

Keywords: neutron diffraction, ceramics, X-ray diffraction
MS14-P4 Novel rehydration mechanism of iron based Layered Double Hydroxides Dörthe Haase ${ }^{\mathrm{a}}$, David F. Sranko ${ }^{\mathrm{b}}$, Sofie E. Canton ${ }^{\mathrm{a}, \mathrm{c}}{ }^{a} M A X-I V$ laboratory, Lund University, Sweden, ${ }^{b}$ Department of Inorganic and Analytical Chemistry, University of Szeged, Hungary, ${ }^{c}$ Department of Synchrotron Radiation Instrumentation, Lund University, Sweden

E-mail: dorthe.haase@maxlab.lu.se

Layered double hydroxides (LDHs) are anionintercalated inorganic functional materials, also known as hydrotalcite-like compounds or anionic clays [1].

The rehydration mechanism of layered double hydroxides containing various di- and trivalent metals were studied using in-situ XRD. The samples CaFe LDH, MgFe LDH, CaAl $\mathrm{LDH}$ and $\mathrm{MgAl} \mathrm{LDH}$ were dehydrated prior to the experiment, leaving a layered structure to be exposed in-situ to a rehydration cycle. Nitrogen gas acted as carrier for an ethanol/water mixture at ambient temperature. It was found that the mechanism of rehydration for $\mathrm{Ca}(\mathrm{II}) / \mathrm{M}$ (III) LDHs differs from that for $\mathrm{Mg}(\mathrm{II}) / \mathrm{M}(\mathrm{III}) \mathrm{LDHs}$. The basal distance changes gradually for the $\mathrm{Mg}(\mathrm{II}) / \mathrm{M}(\mathrm{III})$ LDHs. This is, however, a much faster and nearly one-step process for the $\mathrm{Ca}(\mathrm{II}) / \mathrm{M}$ (III) LDHs. The rate of the rehydration also depends on the composition of the material. The LDHs with aluminium as the trivalent metal need more time than those containing iron and calcium. The profound difference in the rehydration mechanism is most probably associated with the different rigidities of the layers: magnesium containing layers seem to be more flexible than calcium containing ones. The rigidity is also thought to be crucial in determining the affinity of the organic anions to be intercalated, and thus, it is expected to influence the rate of the intercalation.

[1] Evans, D. G., Slade, R.C.T. (2006). Struct. Bond. 119

Keywords: layered structure; hydration; in-situ powder diffraction 